\title{
The implications of a robust curriculum in introductory mechanics
}

\author{
Chance Hoellwarth and Matthew J. Moelter
}

\begin{abstract}
We have developed a curriculum for introductory mechanics that emphasizes interactive engagement and conceptual understanding using the studio format. As previously reported, we have shown in three different quarters that the curriculum much improved the students' conceptual understanding compared to the traditional course without significantly affecting the scores on a traditional final exam. Here we report the results for the entire three-year period during which the course was taught, 34 sections of the course were taught with 11 different instructors to over 1200 students. In each term, these sections had common exams, syllabus, and schedule. Student experiences were very similar in terms of activities. Student performance was measured using the force and motion conceptual evaluation or the force concept inventory; the average pre/post normalized gain was 0.59 . There was no significant correlation with any instructor characteristics, including teaching experience, knowledge of interactive-engagement methods, and attitudes. Because the instructor characteristics are not important, it is the structure of the course that promotes the learning gains.
\end{abstract}

[DOI: $10.1119 / 1.3557069]$

\section{INTRODUCTION}

Over the past few decades, the physics community has invested heavily in studying and developing tools to help students understand Newtonian mechanics ${ }^{1,2}$ and tools to assess that understanding. ${ }^{3,4}$ By using the force concept inventory (FCI), Hestenes found that in conventional instruction student learning is nearly independent of the instructor. $\mathrm{Hake}^{6}$ confirmed this result and showed that interactiveengagement methods could improve students' knowledge gain in conceptual areas more than conventional instruction. Hake defined interactive-engagement methods as those that promote conceptual understanding through interactive engagement of students in heads-on and hands-on activities which yield immediate feedback. ${ }^{6}$

The average normalized learning gain is defined as

$$
\langle g\rangle=\frac{\langle\text { post }\rangle-\langle\text { pre }\rangle}{100-\langle\text { pre }\rangle},
$$

where $\langle$ pre $\rangle$ is the average of the student scores in a section of the course before instruction, and 〈post $\rangle$ is the average of the student scores in the same section after instruction. For interactive-engagement courses, these gains were almost two standard deviations higher than traditionally taught courses, but there is still a large variation in gains among interactiveengagement courses. A large fraction of interactiveengagement courses have gains spread fairly evenly between 0.36 and 0.68 . This spread could be due to an intrinsic difference between interactive-engagement methods, ${ }^{4,7,8}$ or it could be due to implementation differences. ${ }^{7,9}$ One of the reasons for implementations not being equally successful is that many instructors do not implement the interactiveengagement approach in its entirety, or they implement parts of different activities, thus potentially eliminating important parts or coherence.

Usually, an instructor plans the activities and executes them. As the planner, the instructor will affect the implementation, but it is not as obvious what impact the instructor has once the plan has been determined.

We have taught an interactive-engagement, introductory studio physics course at Cal Poly. As previously reported, we have shown that in three different quarters, the interactiveengagement course dramatically improved students' conceptual understanding compared to the traditional course without significantly affecting scores on a traditional final exam. ${ }^{10}$ The course ran for three years $(1998-2001)$. During this time, 11 different instructors at different stages of their careers taught approximately 1200 students in 34 different sections. The sections had the same structure (readings, homework, and tests). The students experienced essentially the same activities in each section. We found that all sections had similar gains on the FCI or FMCE, independent of instructor, and when during the three-year period the course was taken.

\section{DESCRIPTION AND STRUCTURE OF COURSE}

This section closely follows the discussion in Ref. 10. The Cal Poly Studio Classroom opened in the 1998 winter quarter. The primary goals of this environment are to eliminate the boundary between lecture and laboratory and to promote active-learning instruction. The physical layout was based 
loosely on the Rensselaer model. ${ }^{11}$ The studio class size was usually 40 students, and there was a computer for each pair of students.

Calculus-based introductory physics was taught in the studio classroom from 1998 to 2001 to a subset of the offered sections. The course covered introductory mechanics through rotational dynamics. This coverage was usually the same as the traditionally taught sections, although some traditional sections covered angular momentum and static equilibrium as well. The computers were used for classroom activities which included RealTime Physics experiments, ${ }^{2}$ Interactive Lecture Demonstrations, ${ }^{12}$ some analysis of VideoPoint ${ }^{13}$ motion movies, and similar activities developed at Cal Poly. RealTime Physics experiments ${ }^{2}$ use force and motion probes to obtain data; the students make predictions and then verify or resolve their predictions with measurements. Interactive Lecture Demonstrations have students make predictions and then verify or resolve their predictions with measurements by the instructor. These activities are grounded in physics education research and are designed to promote conceptual understanding and the laboratory skills necessary to reach conclusions based on experimental data. The computers were not used for simulations or spreadsheets.

The studio classes met in two-hour blocks three times a week for a total of six hours. Class time was primarily divided between computer-based activities (including experiments) and small-group work. The group work consisted of guided discussions, pencil-and-paper exercises, and practice problem solving. Individual instructors were free to mix and match the various components. Instructor-focused activities were limited to summaries and modeling problem solving. The studio course used the textbook Physics: A Contemporary Perspective by Knight, ${ }^{14}$ which is designed to support an active-learning environment. Because there was very little lecturing, students had to acquire basic information by reading the textbook, which was strongly encouraged by almost a daily collection of exercises from the student workbook that accompanies Knight. ${ }^{15}$

Each quarter, three to five instructors taught one or more sections of the studio course. Before the quarter started, the instructors agreed on the readings, workbook exercises, homework problems, and exam schedule. All sections took the same exams on the same day at the same time. The instructors meet to write the exams, which were traditional with conceptual leanings.

There was no enforced structure during class time. There was a collection of laboratory activities, worksheets, and practice problems from which instructors chose. Initially, we outlined the suggested experiments for the coming week, which eventually led to a "day-by-day" plan that outlined the suggested activities for each day of the quarter. An example is shown in Fig. 1. At the top is a detailed list of suggested activities with approximate times, followed by the "big idea" of the day. Instructors mostly followed this outline, especially with respect to the laboratory activities because of the logistics involving equipment. Instructors made individual choices in terms of the worksheets and problems. From conversations at weekly meetings, we estimate that students from different sections had essentially the same experiences about $85 \%$ of the time, and similar experiences about $95 \%$ of the time.

The most important feature of these common experiences was that students spent more time actively doing physics. In the traditional class, the six hours per week are divided be-

\section{Day 8}

Homework Due
- Workbook Chapter 4 (12-16,18-24)

Schedule

- Questions [10 min.]

- Quiz \#3a kinematics [15 min.]

- Discussion: How to identify forces [25 min.]

- Identifying forces (worksheet-web)

- RTP Lab 3 inv 2 [55 min.]

have them put extra mass on the car for Inv \#2

\section{Other Activities/Problems}

- Pepsi on incline (worksheet-web) [20 min.]

\section{Main Ideas: \\ - Identify forces \\ - Free-body diagrams}

Fig. 1. An example of a page (day 8) from the daily plan that was used by all instructors. The workbook exercises, discussion, RealTime Physics activity, and web worksheet were common to all sections.

tween passive lectures and "cookbook" laboratories. Specifically, the three most important interactive-engagement elements were the RealTime Physics activities, Knight's workbook problems, and group problem solving.

\section{INSTRUCTOR POPULATION}

We administered a brief survey to the instructors who taught in the studio environment, asking them about their use of interactive engagement before and after teaching in the studio, their attitude toward physics education research before and after the studio, their feelings about the studio as implemented, and their feelings about the potential of the studio mode (independent of our implementation). The instructors ranged from those with less than five years of experience to those close to retirement $(30+$ years of experience). Over half (6 of 11) had never used interactiveengagement methods prior to teaching in the studio classroom; the remaining half had used it to varying degrees. Even though many had not used interactive engagement before, almost all the instructors had a positive attitude toward physics education research and most were positive about their experience teaching in the studio classroom. Three instructors changed their attitude about physics education research from positive to neutral or negative and stopped using interactive methods. In at least one case, this change had more to do with our rigid implementation of components of physics education research (it was difficult to do your own thing or change an assignment due date) rather than physics education research itself. Five of the six who had never used interactive-engagement methods are still using them today. 


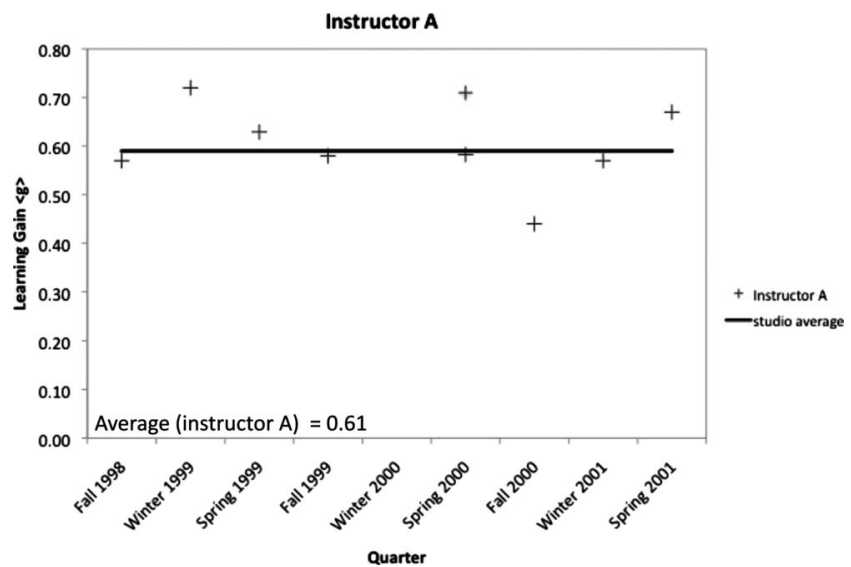

Fig. 2. The learning gain $\langle\mathrm{g}\rangle$ for all studio physics sections taught by instructor A over the entire time of the study. The gains for instructor A vary from section to section.

\section{STUDENT POPULATION}

We examined the composition of the student groups in terms of their academic background, and presented the results for a subset of the students in Ref. 10, showing that over three different quarters (and 13 sections), there were no statistically significant differences among students in different studio sections as indicated by their high school gradepoint averages and SAT scores.

\section{RESULTS}

\section{A. Variation between sections with the same instructor}

Instructor A taught in the studio classroom all nine quarters of this study. The learning gains for these classes are plotted in Fig. 2. The average gain is 0.61 with a high of 0.72 and a low of 0.44 . These gains are the highest and lowest gains found for all of the studio instructors. This variation is larger than we expected given that the instructor is the same, the student body is homogeneous, and the classroom structure and activities were similar from quarter to quarter.

This variation is further illustrated by looking at the Spring 2000 data. In this quarter, instructor A taught two studio sections in the same manner. The learning gains for

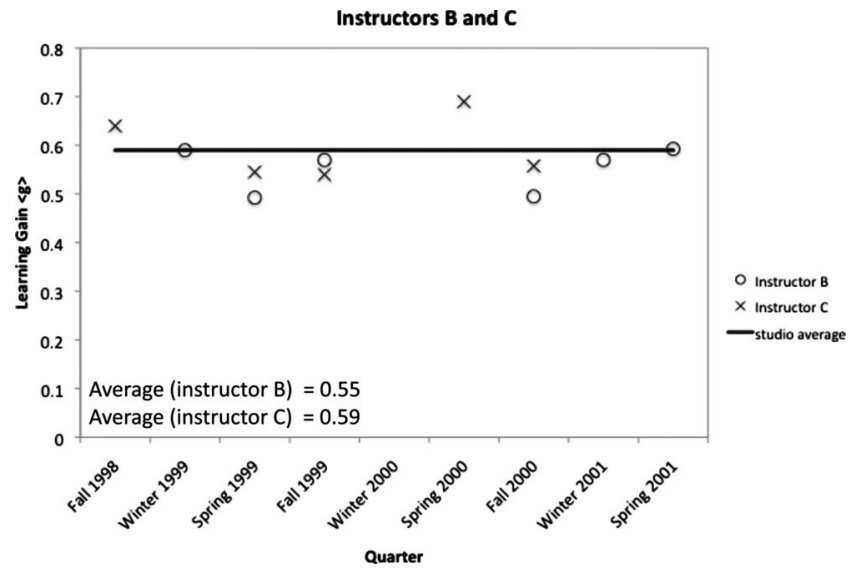

Fig. 3. The learning gain $\langle\mathrm{g}\rangle$ for all studio physics sections taught by instructors $\mathrm{B}$ and $\mathrm{C}$ over the entire time of the study. The variability for instructors B and C is similar to that of instructor A (see Fig. 2).
Table I. Force and motion conceptual evaluation. The average pretest score, the average post-test score, and the Hake gain $\langle\mathrm{g}\rangle$ for each section are given. The FCI was used in Fall 1998. The FMCE pretest was not given in Winter 2000. The gains are approximately the same across all sections over the three-year period.

\begin{tabular}{|c|c|c|c|c|}
\hline Quarter & Instructor & Pre & Post & Gain \\
\hline \multirow[t]{5}{*}{ Fall 1998 (FCI) } & A & 46.0 & 76.8 & 0.57 \\
\hline & $\mathrm{L}$ & 53.2 & 82.1 & 0.62 \\
\hline & $\mathrm{C}$ & 50.6 & 82.6 & 0.64 \\
\hline & $\mathrm{D}$ & 49.3 & 79.2 & 0.58 \\
\hline & G & 44.8 & 78.1 & 0.60 \\
\hline \multirow[t]{5}{*}{ Winter 1999} & A & 26.0 & 79.5 & 0.72 \\
\hline & $\mathrm{D}$ & 35.1 & 72.0 & 0.57 \\
\hline & K & 30.1 & 75.5 & 0.65 \\
\hline & B & 33.8 & 72.5 & 0.59 \\
\hline & $\mathrm{E}$ & 39.0 & 83.0 & 0.72 \\
\hline \multirow[t]{5}{*}{ Spring 1999} & A & 26.8 & 72.8 & 0.63 \\
\hline & $\mathrm{C}$ & 22.4 & 64.7 & 0.55 \\
\hline & B & 24.9 & 61.9 & 0.49 \\
\hline & $\mathrm{D}$ & 23.9 & 59.9 & 0.47 \\
\hline & $\mathrm{H}$ & 18.4 & 65.7 & 0.58 \\
\hline \multirow[t]{4}{*}{ Fall 1999} & $\mathrm{C}$ & 34.7 & 69.9 & 0.54 \\
\hline & $\mathrm{F}$ & 34.6 & 72.6 & 0.58 \\
\hline & A & 35.1 & 71.8 & 0.57 \\
\hline & B & 20.2 & 66.9 & 0.58 \\
\hline \multirow[t]{3}{*}{ Winter 2000} & A & $*$ & 69.5 & $*$ \\
\hline & B & $*$ & 67.9 & $*$ \\
\hline & $\mathrm{E}$ & $*$ & 67.7 & $*$ \\
\hline \multirow[t]{3}{*}{ Spring 2000} & A & 23.0 & 67.9 & 0.58 \\
\hline & $\mathrm{C}$ & 24.7 & 76.5 & 0.69 \\
\hline & A & 34.1 & 81.0 & 0.71 \\
\hline \multirow[t]{3}{*}{ Fall 2000} & A & 22.6 & 57.0 & 0.44 \\
\hline & $\mathrm{B}$ & 34.5 & 66.9 & 0.50 \\
\hline & $\mathrm{C}$ & 35.3 & 71.4 & 0.56 \\
\hline \multirow[t]{3}{*}{ Winter 2001} & A & 23.1 & 66.8 & 0.57 \\
\hline & $\mathrm{B}$ & 36.3 & 72.8 & 0.57 \\
\hline & $\mathrm{J}$ & 32.0 & 73.4 & 0.61 \\
\hline \multirow[t]{3}{*}{ Spring 2001} & A & 25.9 & 75.9 & 0.67 \\
\hline & B & 27.9 & 70.6 & 0.59 \\
\hline & $\mathrm{J}$ & 21.7 & 66.6 & 0.57 \\
\hline
\end{tabular}

these sections were 0.59 and 0.72 . In addition, two other instructors taught five or more studio sections. Their data are plotted in Fig. 3. Instructor B taught in the studio classroom six times and instructor $\mathrm{C}$ taught five times. The average gains for B and C classes were 0.55 and 0.59 , respectively. These instructors showed variations in the learning gain over time similar to instructor A.

Most likely, the variation of the gain is due to small numbers. The average class size was approximately 36 for most classes with an average number of matched pre/post-test scores of about 30 per section. (It is common for students to take the pretest and then drop the course or to add the course after the pretest is given and then take just the post-test.) The reason for the variability is not as important as the fact that it exists and is similar for each instructor.

One way to quantify the variability is to use the standard deviation as the uncertainty. In this case, instructor A's scores can be characterized by $0.61 \pm 0.09$, and the uncertainty in studio scores can then be characterized by the average value of $\pm 15 \%$. 


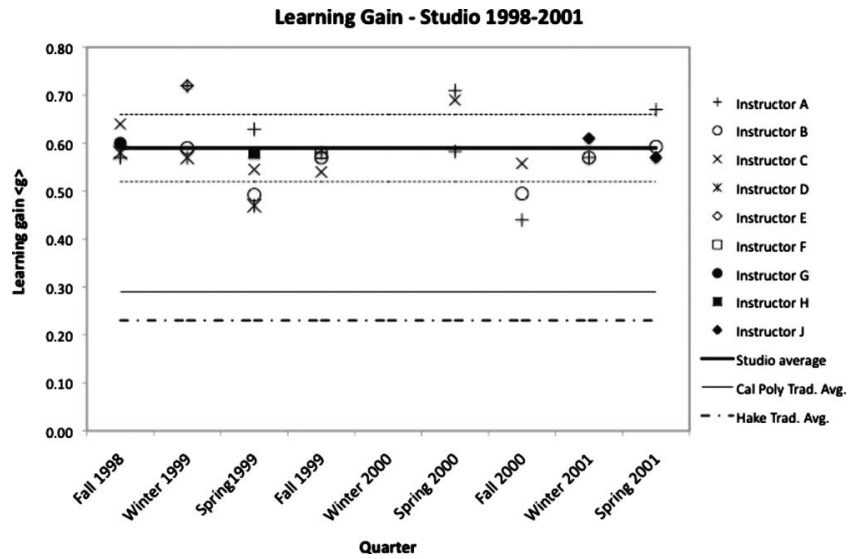

Fig. 4. The learning gain $\langle\mathrm{g}\rangle$ for all the studio physics sections taught during the study. Also shown are the studio average, Cal Poly traditional average, and Hake traditional average. The dashed lines near 0.7 and 0.5 represent the observed $\pm 15 \%$ variability. The gains for all sections taught in the studio are significantly higher than the average for Cal Poly traditional sections and the Hake traditional average, independent of the instructor.

\section{B. All instructors and all sections}

The results for 34 sections of studio classes are listed in Table I. The Hake gain was not calculated for the Winter 2000 quarter because we failed to give the pretest that quarter. To better illustrate the variability, the data have been plotted in Fig. 4. We have also indicated the studio course average (0.59) and the average for nine sections of the traditional course at Cal Poly (0.29), and the average for traditional instruction reported by Hake (0.23). In addition, the average Hake gain for each instructor is shown in Table II. The data confirm the results we presented in Ref. 10: students in the studio course had significantly higher gains on the FMCE than the students in our traditional sections. The sections of all instructors who taught in the studio had much greater gains than the traditional average. These higher gains are significant because the courses were taught by 11 different instructors who varied in their teaching experience and knowledge of physics education research. That the gains occurred across a range of instructors suggests that the structure of the course was largely responsible for these results.

The variability between sections is an average of $\pm 15 \%$, which is about the same as the variability within a section. The two black dashed lines in Fig. 4 indicate the range of class variability. The majority of sections have gains in this range. From looking at the FMCE learning gains, it is impossible to identify the differences between any of the 11 instructors. All instructors who taught this studio course achieved, within the variability, the same gains on the FMCE.

\section{Comparison of outcomes of an instructor who taught using both formats}

To further illustrate that the structure of the course is more important than the instructor for improving the FMCE scores, we look at the scores from a newer instructor who taught using both formats. Instructor J, in his first two years of teaching, taught two sections in the traditional format in the spring of 2000 and then two sections in the studio format in the winter and spring of 2001. In the traditional section, instructor J's students had learning gains of 0.08 and 0.13 , and in the studio sections, just two quarters later, the gains were 0.61 and 0.57 .

There was not sufficient time for instructor $\mathrm{J}$ to significantly change his overall approach to teaching. He taught in the studio to "try something new." He did not attend workshops on how to improve teacher efficacy, nor did he attend workshops on interactive engagement. We conclude that the structure of the studio course itself promoted the learning gains for instructor J's students.

\section{DISCUSSION}

What is it about the structure of the course that made the difference? It is tempting to say that the studio mode made the difference, but Cummings et al. ${ }^{11}$ showed that the studio mode alone did not produce learning gains. They found that using tested interactive-engagement materials did produce gains. The learning gains are due to the materials that were used, the RealTime Physics laboratories, the Knight workbook, and group problem solving. The studio allowed the use of more interactive-engagement curricula; however, this use doesn't explain the consistency of the gains for all 11 instructors.

We believe that the consistent student gains are due to the instructors teaching essentially the same course. They all had students do similar activities, assigned the same workbook problems and end-of-chapter problems, gave the same exams, and graded them in common. Of particular note is not that a course that used interactive-engagement produced gains, it is that 11 autonomous physics instructors taught the same course the same way for three years. How did this happen? The studio made the difference by putting the instructors in a very new environment. In the traditional course, the instructors had a total control of the lecture $(3 \mathrm{~h})$, but the laboratory $(3 \mathrm{~h})$ was largely determined by that

Table II. The average Hake gain $\langle\mathrm{g}\rangle$, the number of sections taught, the standard deviation, and the standard deviation of the mean for all the instructors and each individual instructor are shown. The FCI was used in Fall 1998. The FMCE pretest was not given in Winter 2000. The gains are approximately the same for all instructors.

\begin{tabular}{|c|c|c|c|c|c|c|c|c|c|c|c|c|}
\hline & \multicolumn{12}{|c|}{ Instructor } \\
\hline No. of sections & 31 & 9 & 6 & 5 & 3 & 1 & 1 & 1 & 1 & 2 & 1 & 1 \\
\hline Stdev & 0.07 & 0.09 & 0.05 & 0.07 & 0.06 & $\cdots$ & $\cdots$ & $\cdots$ & $\cdots$ & $\cdots$ & $\cdots$ & $\cdots$ \\
\hline Stdev of mean & 0.01 & 0.03 & 0.02 & 0.03 & 0.04 & $\cdots$ & $\ldots$ & $\ldots$ & $\ldots$ & $\ldots$ & $\ldots$ & $\ldots$ \\
\hline
\end{tabular}


week's experiment. Thus, the six hours of class time became two three-hour experiences that were further disjointed by the fact that the students in each laboratory typically had different lecture instructors. In addition, the laboratory could occur at any time during the week. In contrast, the studio offered one coherent six-hour experience.

It was not possible to just use old examples, laboratories, and story lines in the new mode. Four of the eleven instructors taught the course only once, and three taught the course two times. Therefore, seven of the eleven instructors were not there to make changes, but to implement and try a new mode. To minimize the uncertainty, the initial instructors decided to give common assignments and exams, and to grade them in common, which became the tradition. The initial group did the same activities as well, but after a few quarters, there were too many activities, so instructors had to choose. This choice gave rise to some difference in activities and problems, but students did the same activities $85 \%$ of the time and had similar experiences $95 \%$ of the time. We emphasize that the similarity of experience was students doing activities. Because of the nature of the activities and the structure of the room, it was difficult for an instructor to dominate the course as is possible in a traditional lecture.

In summary, if instructors teach the same way, they obtain the same results, taking into account some variation in the students. This similarity is what Hake's study showed about traditional instruction: if you lecture to students, you obtain certain results on the FCI. We have shown that if instructors use the same interactive-engagement materials in the same way, they will get the same results, in this case higher gains on the FMCE. The difference is not the instructor, but rather what the students are doing. Students learn from their experiences: the experiments they do, the demonstrations they see, the questions they ask and are asked, and the mode in which these occur. The implication is that student experiences are the most important factor for producing learning gains, not the instructor.

Why was the studio physics mechanics course taught for such a short time? In our department, we have just one studio classroom. In a typical quarter, we teach a dozen or so sections of each of three courses in the introductory calculusbased sequence and about half that number of the algebrabased sequence. Therefore, only a fraction of the sections of one course can be taught in the studio during a quarter. Given this limitation, our studio classroom has been used to test active-learning strategies in a variety of courses. In addition to the course described in this paper, we have taught introductory mechanics for the algebra-based sequence, traditional RealTime Physics laboratories for electromagnetism, thermodynamics and vibrations and waves, sophomore-level modern physics, and physics on the computer. Most recently, we have been using the studio classroom for a three-quarter sequence of courses in physical science as part of our program in liberal studies geared toward future teachers. In each case, the studio environment and the interactive-engagement methods have been successful in terms of student learning. As a result, the university has plans for a new building which will include more studio classrooms.

Some instructors have modified the studio materials and activities for a more traditional lecture format (four 50minute lectures, but no laboratory). The course included little lecturing, interactive lecture demonstrations, and group activities - both conceptual and numerical. Seven tenuretrack faculty and lecturers have implemented the plan in six different quarters to 27 sections. The average gain has been $0.48 \pm 0.01$ (uncertainty is the standard deviation of the mean). The range was $0.30-0.56$, a range similar to the studio data. Although the results are not as high as the studio course, they are better than the traditional method, indicating that it is possible to port the studio learning experiences to other environments.

\section{IMPORTANCE OF CAREFULLY DESIGNED EXPERIENCES}

Carl Wieman has stated that "teachers spend enormously more time worrying about their lectures than they do about their homework assignments, which I think is a mistake. ... To ensure that the necessary extended effort is made, and that it is productive, requires carefully designed homework assignments, grading policies, and feedback."16 This statement applies to the use of class time as well. Teachers spend much more time worrying about what they are going to tell students than thinking about what experiences they are going to provide for students. To ensure that students learn in class requires carefully designed experiences that keep them engaged and make them think.

\section{ACKNOWLEDGMENTS}

The authors thank our Cal Poly colleagues R. Echols, D. Hafemeister, R. Knight, J. Morris, R. Saenz, N. Sungar, L. Wall, W. Wilson, and R. Zammit for their participation. M. Wittmann of the University of Maine helped analyze the FMCE data. The authors received support from the Department of Education (Grant No. FIPSE 116P980003), administered by D. Sokoloff at the University of Oregon. M.J.M. thanks the faculty of the School of Physics at the Dublin Institute of Technology for their hospitality during a sabbatical leave. C.H. thanks Bruce Birkett and Shery Hoellwarth for useful comments and encouragement on this manuscript. The authors appreciate the helpful suggestions from two anonymous reviewers that helped clarify the manuscript.

\footnotetext{
a) Electronic mail: choellwa@calpoly.edu

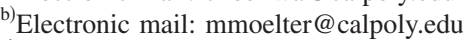

${ }^{1}$ Lillian C. McDermott and Edward F. Redish, "Resource Letter: PER-1: Physics education research," Am. J. Phys. 67 (9), 755-767 (1999); Edward F. Redish, Teaching Physics with the Physics Suite (Wiley, Hoboken, NJ, 2003); David R. Sokoloff and Ronald K. Thornton, "Using interactive lecture demonstrations to create an active learning environment," Phys. Teach. 35 (6), 340-347 (1997).

${ }^{2}$ David R. Sokoloff, Ronald K. Thornton, and Priscilla W. Laws, RealTime Physics: Active Learning Laboratories (Wiley, New York, 1999).

${ }^{3}$ David Hestenes, Malcolm Wells, and Gregg Swackhamer, "A mechanics baseline test," Phys. Teach. 30 (3), 159-166 (1992); David Hestenes, Malcolm Wells, and Gregg Swackhamer, "Force concept inventory," ibid. 30 (3), 141-158 (1992).

${ }^{4}$ Ronald K. Thornton and David R. Sokoloff, "Assessing student learning of Newton's laws: The force and motion conceptual evaluation and the evaluation of active learning laboratory and lecture curricula," Am. J. Phys. 66 (4), 338-352 (1998).

${ }^{5}$ I. A. Halloun and D. Hestenes, "The initial knowledge state of college physics students,” Am. J. Phys. 53 (11), 1043-1055 (1985).

${ }^{6}$ R. R. Hake, "Interactive-engagement versus traditional methods: A sixthousand-student survey of mechanics test data for introductory physics courses," Am. J. Phys. 66 (1), 64-74 (1998).

${ }^{7}$ Ronald K. Thornton, Dennis Kuhl, Karen Cummings, and Jeffrey Marx, "Comparing the force and motion conceptual evaluation and the force concept inventory,” Phys. Rev. ST Phys. Educ. Res. 5, 010105 (2009).

${ }^{8}$ Catherine H. Crouch and Eric Mazur, "Peer instruction: Ten years of
} 
experience and results," Am. J. Phys. 69 (9), 970-977 (2001).

${ }^{9}$ Michael C. Wittmann, "Continuing evaluation of secondary implementation of RealTime Physics and Interactive lecture demonstrations,' 〈perlnet.umephy.maine.edu/research/mow.htm〉; Adam P. Fagen, Catherine H. Crouch, and Eric Mazur, "Peer instruction: Results from a range of classrooms," Phys. Teach. 40 (4), 206-209 (2002); N. D. Finkelstein and S. J. Pollock, "Replicating and understanding successful innovations: Implementing tutorials in introductory physics." Phys. Rev. ST Phys. Educ. Res. 1, 010101 (2005)

${ }^{10}$ C. Hoellwarth, M. J. Moelter, and R. D. Knight, "A direct comparison of conceptual learning and problem solving ability in traditional and studio style classrooms," Am. J. Phys. 73 (5), 459-462 (2005).
${ }^{11}$ K. Cummings, J. Marx, R. Thornton, and D. Kuhl, "Evaluating innovation in studio physics," Am. J. Phys. 67 (7), S38-S44 (1999).

12 "Tools for scientific thinking-Interactive lecture demonstrations," Vernier Software, Beaverton, OR.

${ }^{13}$ VideoPoint, Lenox Softworks, Lenox, MA.

${ }^{14}$ Randall D. Knight, Physics for Scientists and Engineers: A Strategic Approach (Addison-Wesley, New York, 1997) (preliminary edition).

${ }^{15}$ Randall D. Knight, Student Workbook to Accompany Physics for Scientists and Engineers: A Strategic Approach (Addison-Wesley, New York, 1997) (preliminary edition).

${ }^{16}$ Carl Wieman, "Why not try a scientific approach to science education?," Change 39 (5), 9-15 (2007). 